Bol. Acad. peru. leng. 61.2016 (183-198)

\title{
Clorinda Matto de Turner en Buenos Aires: carta inédita a Robert Lehmann-Nitsche (01/02/1906)
}

\section{Clorinda Matto de Turner in Buenos Aires: an unpublished letter to Robert Lehmann-Nitsche (02/01st /1906)}

\author{
Ena Mercedes Matienzo León \\ Pontificia Universidad Católica del Perú
}

Resumen:

El siguiente documento tiene como finalidad dar a conocer una carta que la escritora peruana Clorinda Matto de Turner dirigió desde Buenos Aires en 1906 al antropólogo físico y etnólogo Robert Lehmann-Nitsche. La misiva, que está escrita a mano, y en la que se halla la firma de la polígrafa cusqueña, se encuentra guardada en la biblioteca del Instituto Ibero-Americano de la ciudad de Berlín en la sección de legados, autógrafos, dibujos y otras documentaciones fotográficas. Este breve estudio es una primera pesquisa sobre un amplio registro epistolar que posiblemente dirigió Matto de Turner a personalidades académicas, políticas y religiosas. La publicación de esta primera carta ofrece información sobre los espacios en los que se movilizó la escritora peruana a inicios del siglo XX. 


\section{Abstract:}

The following paper is intended to reveal a letter that Peruvian writer Clorinda Matto de Turner addressed from Buenos Aires, in 1906, to physical anthropologist and ethnologist Robert Lehmann-Nitsche. The letter that is written by hand, and it is visible the Cusco poligrapher's signature, is preserved in the library of the Ibero-American Institute in Berlin, in the section of legacies, autographs, drawings and other photographic documentations. This brief study is a first research on a wide recorded correspondence that possibly Matto de Turner addressed to some academic, political and religious personalities. The publication of this first letter offers information on the spaces in which the Peruvian writer move at the beginning of the 20th century.

Palabras clave: Clorinda Matto de Turner, correspondencia, novela, Aves sin nido.

Keywords: Clorinda Matto de Turner, correspondence, novel, Birds without a nest.

Recibido: 31/08/2016 Aceptado: 30/09/2016

\section{Buenos Aires, el punto de encuentro}

La pluma limeña decimonónica, encabezada por la dama argentina Juana Manuela Gorriti, de gran influencia en el ambiente literario limeño, rendía pleitesía en 1877 a Clorinda Matto de Turner, una escritora provinciana de solo veinticinco años de edad. 
El momento de reconocimiento es descrito por el insigne peruano Abelardo Gamarra con las siguientes palabras:

Con sus propias manos la señora Gorriti adornó las sienes de la hermosa tradicionista con una corona de rica filigrana, semejando las enlazadas ramas del simbólico laurel y colocó en sus manos una valiosa pluma y tarjeta de oro, [...] como recuerdo de sus amigas y homenaje de sus hermanas en las letras. (1890: VI)

Aves sin nido, su novela cumbre, aparecía en 1889, año en que asume además la dirección de El Perú Ilustrado, la más alta tribuna en Lima. Es en este mismo semanario que se publica en agosto de 1890 el cuento «Magdala», del escritor de origen brasilero Henrique Coelho Netto, relato que incluye una escena amorosa entre Jesús y Magdalena. Esta situación, más la postura anticlerical de su primera novela, produjo la «reacción conservadora desde dos frentes, el clerical [...] y el gamonalismo latifundista y explotador del indio» (Nuñez 1976: 7). La adversidad fue extrema a la caída del gobierno de Andrés Avelino Cáceres, por quien la escritora expresó adhesión política pública. Las consecuencias de esta postura fueron asumidas, según palabras de la escritora, con

serenidad, presenciando la destrucción de nuestro hogar, primero, después, la de nuestro taller de trabajo y por último aceptando el camino del extranjero para buscar el pan que no podíamos hallar en aquel suelo cargado de venganzas, de atropellos [...]. (1902: 23-24) 
Clorinda Matto de Turner llega a Buenos Aires el 15 de mayo de 1895 (Ferreira 2005: 119).

En otro espacio, en la lejana Alemania, Robert Lehmann-Nitsche, originario de Posen, antigua provincia prusiana, presenta en 1894 su tesis doctoral en filosofía sobre antropología física de los bávaros, cuyo estudio será premiado por la Sociedad Antropológica de París (Ballestero 2013: 23). En marzo de 1897 concluye su segundo trabajo doctoral en medicina sobre la cirugía prehistórica en base a hallazgos de la antigüedad alemana, disertación que «auguraba un prometedor futuro a la antropología alemana» (Ballestero 2013: 25).

Rudolf Martin, estudioso de la antropología física de la población indígena de Tierra del Fuego, y cuyos contactos se extendían a los medios académicos argentinos, informa a Lehmann-Nitsche del amplio material de estudio que poseía el Museo de La Plata en Argentina. Convence al recién graduado y joven discípulo de asumir el cargo de conservador de la sección antropológica del Museo de La Plata, ante un puesto vacante que se abría. Robert Lehmann-Nitsche con solo veinticinco años de edad arriba a Buenos Aires el 10 de julio de 1897 y ese mismo día «se publica el decreto del nombramiento por el cual es encargado de la sección de antropología del Museo de La Plata» (Ballestero 2013: 69). Este recinto fue su centro de investigación paleoantropológica y un espacio privilegiado de estudios sobre cultura e idioma de los grupos aborígenes del cono sur a lo largo de treinta años. 


\section{La edición valenciana e inglesa de Aves sin nido y los nuevos lectores de Clorinda Matto de Turner}

La publicación de Aves sin nido por la editorial valenciana F. Sempere y Compañía, Editores, en 1900, posiciona la novela de Matto de Turner en el repertorio bibliográfico europeo y abre un nuevo auditorio de lectores. El responsable de esta edición fue Francisco Sempere Masiá cuyo proyecto editorial estuvo dirigido a divulgar libros de carácter científico y laico del pensamiento europeo del siglo XIX ${ }^{1}$. Para principios del siglo $X X$, esta casa editorial poseía sucursales en Madrid y Barcelona y una oficina central ubicada en la ciudad de Valencia. En el libro Viaje de recreo. España, Francia, Inglaterra, Italia, Suiza y Alemania, la escritora Matto de Turner nos ofrece un testimonio sobre su llegada a España -el desembarco en Barcelona y el viaje a Madrid por Valencia- y su encuentro con Francisco Sempere. Para la escritora peruana, los libros publicados por el editor valenciano asociado con Vicente Blasco Ibañez son preferidos por la juventud de América "porque entre sus similares aporta mayor contingente a la cultura y a la libertad del pensamiento» (Matto de Turner 1909: 32). La amplia estima de la autora de Aves sin nido hacia su editor es expresada en las siguientes líneas:

anunciaron a Francisco Sempere, presentándose en

1 La contribución de esta casa editorial significó una labor de divulgación de libros de alta calidad a precios accesibles y que incluye la valiosa labor de traducción de libros del pensamiento europeo a la lengua castellana como ¿Qué es propiedad?, de Pierre-Joseph Proudhon; Estudios religiosos, El porvenir de las ciencias, de Ernest Renan; La libertad, El amor, las mujeres y la muerte, de Arthur Schopenhauer; La psicología del socialista anarquista, de Augustin Hamon; El capital (2 tomos), de Karl Marx para citar los más importantes títulos. 
seguida un caballero esbelto, en cuya frente ancha y levantada se refleja el pensamiento reposado y una bondad ingénita, pregonada por sus ojos de mirada honda. Nos estrechamos la mano como dos antiguos amigos [...]. (Matto de Turner 1909: 34)

La novela peruana publicada en Valencia contiene un juicio crítico de Emilio Gutiérrez de Quintanilla, quien es correspondiente de la Real Academia Española y en ella señala indubitable que «El pensamiento primordial de la autora es que la raza indígena sea [...] incorporada a nuestra racionalidad y cultura por la igualdad civil» (Matto de Turner 1900: 5). Este juicio preliminar sobre la novela peruana establece coincidencias entre los libros de carácter progresista de la editorial de Francisco Sempere y la defensa ilustre hacia los indios peruanos desde el «terreno literario».

En 1904 aparece publicada en Londres la edición en inglés de Aves sin nido bajo el título Birds Without a Nest. A Story of Indian Life and Priestly Opression in Peru. El prefacio de la edición inglesa fue escrito por Andrew M. Milne, agente de la Sociedad Bíblica Americana de las Repúblicas del Río de La Plata, Chile, Ecuador, Perú y Bolivia. El autor del prefacio afirma ser conocedor de la realidad andina y por tanto expresa simpatía por los ideales de la escritora a favor de la «raza quechua»: «I am in deepest sympathy with every effort to ameliorate the condition of the Indian, and I am well acquainted with the writer» (Matto de Turner 1904: VII). El nombre de este personaje inglés se distinguirá además en la edición de las traducciones de textos bíblicos al quechua realizada por 
Matto de Turner radicada en Argentina. El reverendo «Andrés Murray Milne» es quien le encomienda esta labor en Buenos Aires, según se lee en la carta que la novelista peruana le envía a modo de agradecimiento por la designación para «emprender tarea de tanta significación y peso». Advierte la autora que la traducción será al quechua "vulgarizado», pues afirma que «la obra responderá al propósito de que la palabra divina sea conocida en todas las regiones sudamericanas que todavía conservan ese idioma [...] y con el Evangelio irá la luz y el consuelo a los hogares indígenas» (Matto de Turner 1912 pp. 3-4)². Su residencia en Buenos Aires y las dos ediciones europeas de Aves sin nido expresan una expansión a espacios intercontinentales, sin olvidar su impulso incesante «en favor de los indios del Perú».

La correspondencia de Matto de Turner dirigida al Rev. Andrew M. Milne de 1901, así como la misiva dirigida al Dr. Robert Lehmann-Nitsche de 1906, que en este breve estudio se hace pública, alude a un tema que no es posible obviar y es aquello que la crítica literaria ha denominado «indigenismo romántico». En otros términos, el constante llamado de la autora peruana al consuelo de «los hogares indígenas» o como

2 La carta ha sido reproducida en la segunda edición bilingüe de Apunchis Jesu-Cristoc Evangelion. San Lucaspa Qquelkascan de 1912. La primera edición fue publicada en Buenos Aires en 1901. Cabe mencionar que la biblioteca del Instituto Riva Agüero de la ciudad de Lima guarda dos textos bíblicos traducidos al quechua por Clorinda Matto de Turner. El primero es San Pablo Apostolpa Romanocunaman Qquelkascan. Posiblemente este texto sea la primera edición bonaerense de 1901, el año de publicación es obviado en el texto. El segundo texto es Apunchis Jesu-Cristoc Evangelion. San Lucaspa Qquelkascan, edición de 1912 publicada en Lima. Igualmente se pueden hallar las ediciones de los textos quechuas en la Biblioteca Pública de la Universidad de La Plata y de la Universidad de Buenos Aires. 
la mención que hace en el proemio de Aves sin nido de pretender «mejorar la condición de los pueblos chicos del Perú [...] recordando que [...] existen hermanos que sufren, explotados en la noche de la ignorancia», permite visualizar una imagen «ideal» y romántica de aquellos a quienes defienden y protegen, un anhelo constante de revertir tal situación con acciones concretas como la publicación de textos en beneficio de los «martirizados en esas tinieblas que piden luz» (Matto de Turner 1994: 4) .

\section{Carta a Robert Lehmann-Nitsche uen favor de los indios del Perú»}

Mientras tanto entre el período de 1900 a 1906 el estudioso alemán Robert Lehmann-Nitsche, ya radicado en Buenos Aires, realiza dos viajes a Europa con la finalidad de participar en congresos y reuniones científicas en Alemania, Francia y Austria. El primer viaje es efectuado en 1900, año en que comienza sus estudios de paleoantropología sobre la formación pampeana. Antes de iniciar su segundo viaje a Europa en 1904, Lehmann-Nitsche ya había iniciado sus trabajos de campo en Tierra del Fuego. Un año después de su regreso al Museo de La Plata empieza la gran labor de grabar y registrar música indígena folclórica y popular

3 Sobre este punto, el crítico Antonio Cornejo Polar define bien este término en su estudio Clorinda Matto de Turner, novelista. Estudios sobre Aves sin nido, Índole y Herencia: «La imagen que Aves sin nido ofrece a los indios tiene rasgos marcadamente románticos y de alguna manera se asocia con el estereotipo del "buen salvaje". Los indios son alabados por la "encantadora sencillez de sus costumbres" y aparecen siempre como seres inocentes, buenos y candorosos [...] pero esa misma bondad natural los hace singularmente vulnerables frente a la codicia de los potentados y de las autoridades de la región» (2005: 183). 
en las regiones del cono sur en 1905 y al año siguiente lo designan profesor del Instituto del Museo de La Plata. Posiblemente este ambiente último es el punto de encuentro de los dos distinguidos personajes protagonistas de este breve estudio. La correspondencia de Robert Lehmann-Nitsche es amplia y dirigida a diversas personalidades e instituciones ${ }^{4}$. En la carta de 1906, Clorinda Matto de Turner hace mención a su «distinguidísimo amigo» de una conferencia a la que ella no pudo asistir. Incluye en la misiva una solicitud propia del propósito fundamental de la escritora peruana: elaborar una edición económica o de propaganda de Aves sin nido "por medio de una erogación para costearla». Solicita a Lehmann-Nitsche la ayuda entre sus relaciones para la adquisición de su tercera edición «que se haría en Valencia». La carta hallada en la Biblioteca del Instituto Ibero-Americano no está acompañada de la respuesta del americanista Robert Lehmann-Nitsche, que posiblemente fue respondida en la brevedad y con el compromiso de ayudar a su distinguida amiga que ama «con amor de ternura a la raza indígena».

4 En el archivo de la correspondencia de Robert Lehmann-Nitsche que la Biblioteca del Instituto Ibero-Americano guarda, se hallan contactos con personajes del medio académico y cultural peruano como Ricardo Palma, que dirigió cuatro cartas al americanista alemán entre 1911 y 1915 y una carta de la Sociedad Geográfica de Lima en 1911. Se hallan además diez misivas escritas en alemán de Arthur Posnansky -uno de los primeros estudiosos de El Primer Nueva Corónica y Buen Gobierno- que escribió desde La Paz entre 1909 y 1920 y una constante comunicación entre 1911 y 1924 con Max Uhle desde Santiago de Chile, Lima, Quito y Antofagasta. En el extenso archivo epistolario existen cinco cartas de Luis Valcárcel desde Cuzco y Arequipa entre 1920 y 1921, y una carta del médico y arqueólogo Julio C. Tello en 1923. Se debe añadir a este recuento la correspondencia que mantuvo con damas de relevante labor como Ilse von Rentzell, escritora, fotógrafa, dibujante y andinista de origen alemán, radicada en los Andes argentinos; Carlota Garrido de la Peña, destacada periodista argentina; Caecilie Seler-Sachs, etnóloga y fotógrafa en 1917; solo por mencionar algunas. 


\section{Transcripción de la carta}

Clorinda Matto de Turner ${ }^{5}$

Ibero-Amerikanisches *Institut* Berlin ${ }^{6}$

Buenos Aires, Febrero $1^{\circ}$ de $19[06]^{7}$

Sr. Dr. R. Lehmann Nitsche

La Plata

Mi distinguidísimo Sr. y amigo.

Estoy en deuda con usted. Cuando dió su conferencia recibí su invitación y no pude asistir, porque me llegó atrasada y tampoco me fue dado felicitarlo entonces guardándome para otra ocasión.

Hoy tengo que solicitar su ayuda para un asunto de propaganda en favor de los indios del Perú. Le envío por el correo, junto con ésta, un ejemplar de la traducción inglesa de mi libro "Aves sin nido» para que se digne cederla a la biblioteca de ese museo. Ahora bien. Se trata de hacer una edición económica, de propaganda, del texto castellano por medio de una erogación para costearla. Esta $3^{a}$ edición se hará en Valencia. La erogación sería de una Z E por acción. ¿Le sería posible ayudarme entre sus relaciones? Espero que no dejará de haber algunos correligionarios y amigos que no se muestren indiferentes con una publicación que ha sido de tanto efecto en el Perú como indica el prólogo de la

\footnotetext{
5 El nombre de la escritora se encuentra membretado en la hoja de la carta.

6 En la carta original se muestra el sello del nombre de la institución que la guarda. En español es Instituto Iberoamericano Berlín.

7 El año 1906 tiene escrita las dos últimas cifras con dificultad.
} 
traducción inglesa, aunque ella está no muy bien hecha. Yo no tengo ningún ejemplar castellano para poder mandarle, pues, las dos ediciones hechas se han agotado enteramente.

Deseándole salud y prosperidad, soy su más absoluta amiga Sa Sa,

Clorinda Matto de Turner

S. C. calle Rincón 611 
Anexo

Carta manuscrita de Clorinda Matto de Turner ficorimas thatto de

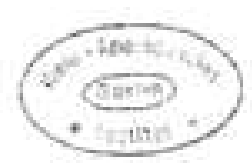

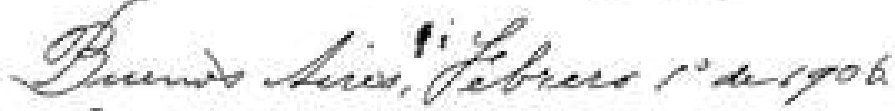
Star

R. Hhemmon MFische

L Sato

lliditingwiving hamir bitg in dende on mety. buand divin en enferencia $\mu$ whisen mitarion $y$ morde ardat, forque me lly, ath sada y tonferes me facida

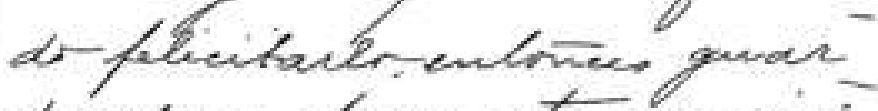
dandome fara otax oexeivi try tengo queveridiar en ayied ban m acumt de pinforganda en favor de law holis del Peraide enví for $l$ cancoif fom to con iétay

194 
en fermplar de la hadoce aid ingleor a mi liker "I ves cim mido" para gue an digme cederla a la bithitiea her muser. Shm hin. Se trata de haver una edición ecomimuea, de fropaganda, def texts-cactellario form mes. de una engacion frasa cortiacta beta sa edvioun se hara'en' Va lencia L errgani ena de una $\& \$$ for aciom. Lle reva prestle aysudame enthe eno relacionos. Bopeer que mor defa - ba'de halaer algmoro carrele. gonarios amian gurnit se muatren inxiferentes on ma fublicacion que ha aito de tanto ofuto en el Rivi

195 


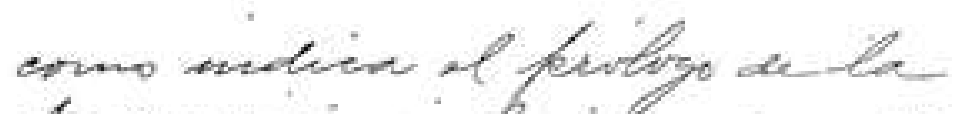

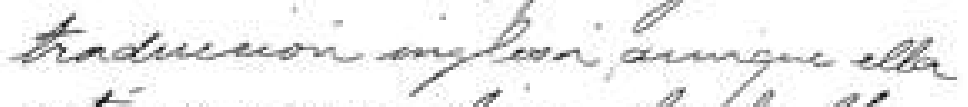
cetio no my hin helha. I\% mp temgo mingem stinglar eacte thes, two dos edveives heches se han agrtadr enterament.

Dexeondole valud firaperidod, ey an mas

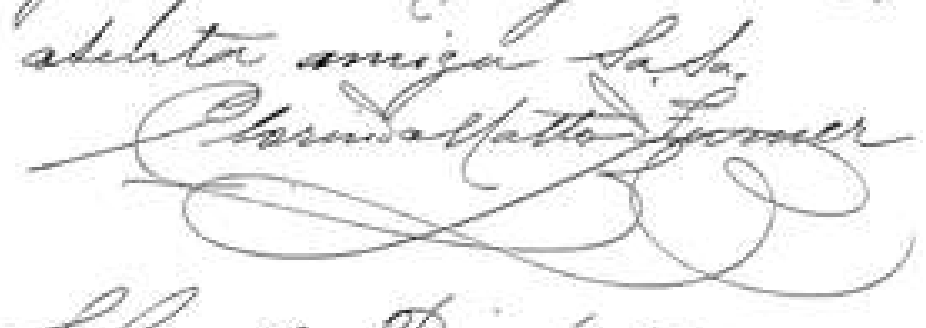

D. b. call OSoncón $\sigma$ N.

196 


\section{Bibliografía}

BALLESTERO, Diego Alberto. Los espacios de la antropología en la obra de Robert Lehmann-Nitsche, 1894-1938. Tesis de doctorado. La Plata, Universidad Nacional de La Plata, Facultad de Ciencias Naturales y Museo, 2013.

CARRILLO, Francisco. Clorinda Matto de Turner y su indigenismo literario. Colección Kipu. Serie Creación y Crítica. Lima, Ediciones de la Biblioteca Universitaria, 1967.

CORNEJO POLAR, Antonio. Literatura y sociedad en el Perú: La novela indigenista; Clorinda Matto de Turner, novelista. Estudios sobre Aves sin nido, Índole y Herencia. Lima, Centro de Estudios Literarios Antonio Cornejo Polar, Latinoamericana Editores, 2005.

FERREIRA, Rocío. «La profesionalización de la periodista y escritora: Clorinda Matto de Turner, obrera del pensamiento», en Literatura y sociedad en el Perú: La novela indigenista; Clorinda Matto de Turner, novelista. Estudios sobre Ave sin nido, Índole y Herencia. Lima, Centro de Estudios Literarios Antonio Cornejo Polar, Latinoamericana. Editores, 2005, págs. 103-127

GAMARRA, Abelardo M. "Apuntes de viaje», en Bocetos al lápiz de americanos célebres de Clorinda Matto de Turner. Tomo I. Lima, Imprenta Bacigalupi, 1890.

MATTO DE TURNER, Clorinda. Aves sin nido. Valencia, F. Sampere y Compañía, Editores, 1900.

. Boreales, miniaturas y porcelanas. Buenos Aires, Imprenta de Juan A, Alsina, 1902, págs. 23-24. 
. Birds Without a Nest: A Story of Indian Life and Priestly Oppression in Peru. Traducción de J. G. Hudson. Prefacio por Andrew M. Milne. Londres, Charles J. Thynne, 1904.

. Viaje de recreo. España, Francia, Inglaterra, Italia, Suiza y Alemania. Valencia, F. Sampere y Compañía, Editores, 1909.

. «Carta a Rev. Sr. Andrés Murray Milne. Buenos Aires, 22 de abril de 1901». La carta ha sido reproducida en la segunda edición bilingüe de Apunchis Jesu-Cristoc Evangelion. San Lucaspa Qquelkascan. Lima, Imprenta El Progreso Editorial, 1912.

. «Proemio», en Aves sin nido. Caracas, Biblioteca Ayacucho, 1994, pp. 3-4.

NUÑEZ, Estuardo. «Prólogo», en Matto de Turner, Clorinda. Tradiciones cuzqueñas completas. Lima, Peisa, 1976, pág. 7. 